\title{
THE BLACK WIDOW SPIDER IN SASKATCHEWAN
}

WAYNE LYNCH, \#104 528 15th Avenue S.W., Calgary, Alberta. T2R OR2

The Black Widow Spiders have acquired an evil reputation, although no one in Canada has ever died from the bite of either of the two species found in this country. In Western Canada, the Black Widow [Latrodectus herperus (Chamberlin \& Ivie)] is very common and widespread throughout the dry grassland regions of southern Alberta and southwestern Saskatchewan, and the arid parts of southern British Columbia, though it is rarely seen. The spider varies greatly in its markings at different stages, and in different regions, but the one unchanging feature of the adult female is the general blackness of her body and legs, and the red hourglass-shaped marking on the underside of her abdomen.
The common name Black Widow refers to the intriguing reproductive strategy that has evolved in the spider. Black Widows build their webs in natural cavities or abandoned rodent burrows. The web of the female Black Widow contains a pheromone (odour hormone) that identifies her to the male spider. At the start of courtship, the male (about 1/10 the size of the female, and patterned in grey, tan and orange) approaches the edge of the female's web and plucks out a vibratory message to her.

Like all web-building spiders, the Black Widow has relatively poor eyesight and she relies on vibrations transmitted through her web to signal the

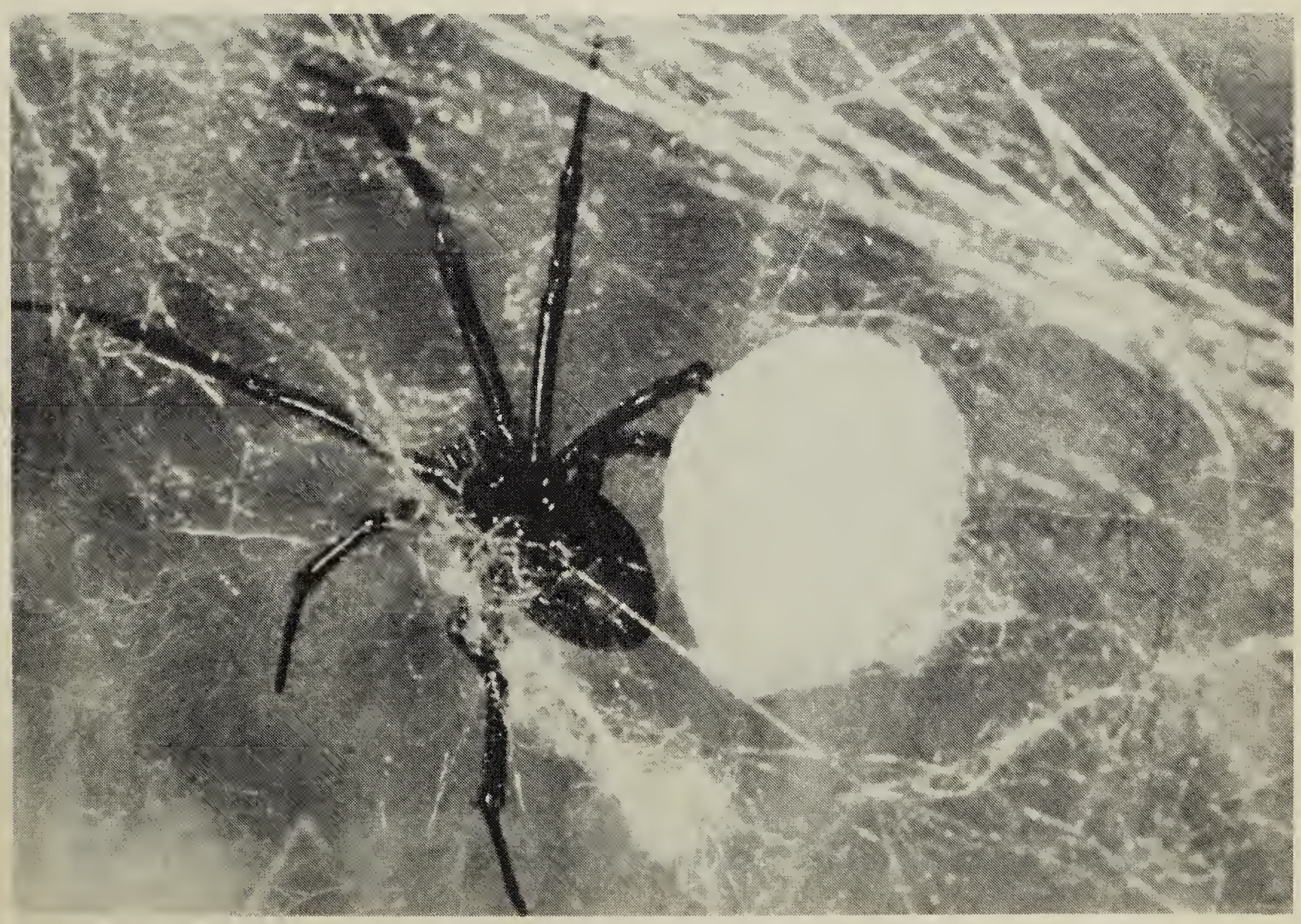


presence of prey, or the approach of a mate. The predatory habits of spiders makes recognition of the sexual partner especially important. If the female is receptive, the male approaches and mating proceeds. Afterwards, the male usually lingers on the female's web and she eats him. In this way the male contributes to the nutritional well being of the female, and increases the likelihood of successful egg laying. The female lays her eggs anywhere from 7 to 305 days after mating.

This was the stage at which I found my Black Widow. I collected her 15 miles west of Consul, Saskatchewan on 23 June 1983. The web was on the superior aspect of an abandoned fox den, about 8-12" back from the upper lip of the burrow. I kept the spider in a 500 milliliter peanut butter jar, and within hours of capture she had spun a disorderly web inside the jar. She spent her time hanging beneath the web, her scarlet hourglass advertising her identity. On the morning of 1 July her abdomen was markedly shrunken and she had spun a globular, creamcoloured, silken egg sac (in the wild the Black Widow prepares one to three egg sacs, but as many as 21 have been reported). For weeks after that she was always beside her eggs, and only left them to feed on dead house flies that I provided. Except for ten days when I kept the spider refrigerated at $50^{\circ} \mathrm{F}$, she and her eggs were maintained at average room temperature. On 17 August there was a tiny hole in the egg sac and the web was sprinkled with 49 spiderlings (egg sacs typically contain 150-600 eggs). In the wild the life span of a Black Widow is rarely as much as a year and they die shortly after laying their eggs. The young spiders disperse soon after hatching to lead solitary lives.

Through the grapevine the Saskatchewan Museum of Natural History learned of my spider, and asked that she and her offspring be donated to

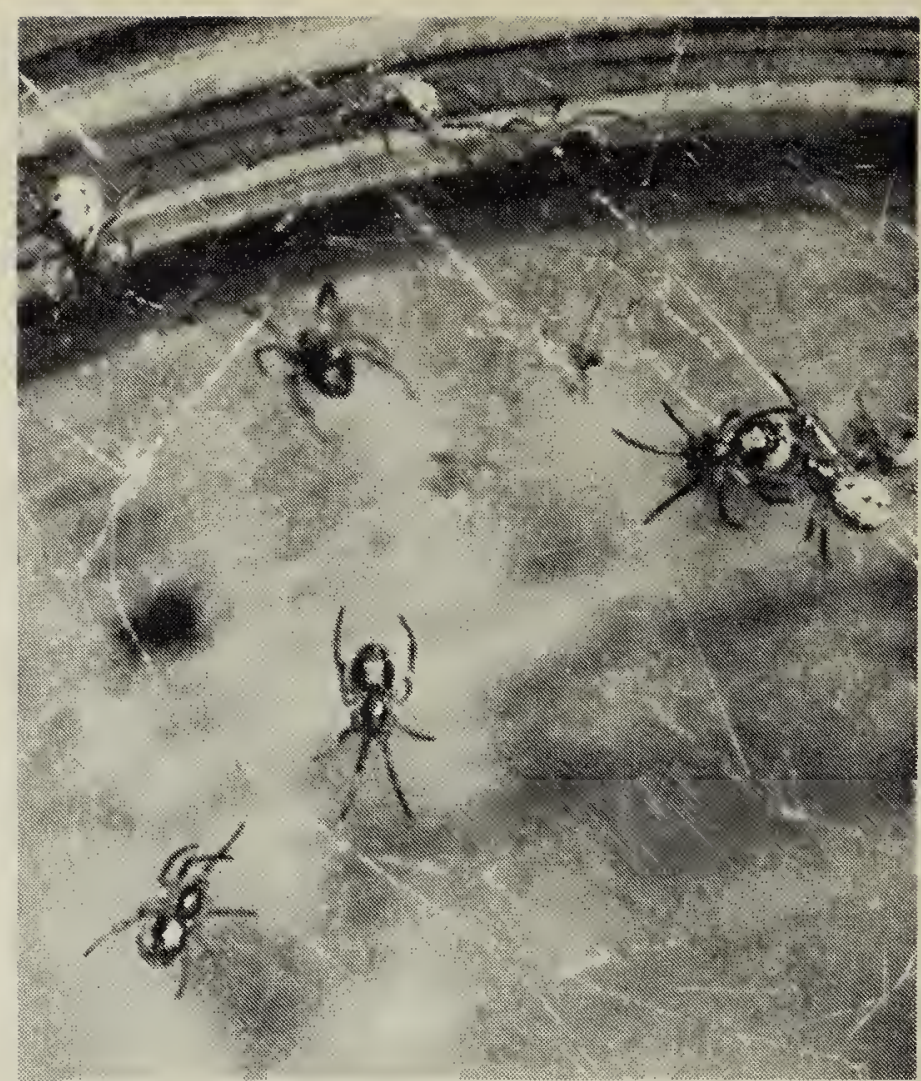

Black Widow spiderlings. Wayne Lynch

the Museum, as there were no Black Widows in their spider collection. It surprised me that so little is known about the spider's distribution in Saskatchewan, and that there are few records of sightings. If any of the readers have seen the Black Widow in the prairies I would appreciate hearing about it. I am particularly interested in the location, date, and circumstances. Please send the data to the author at the address given above. Some useful references are listed below.

CURTIS, L. COLIN. 1980. Black Widow Spiders. Publication 1214, Agriculture Canada. 5 pp.

FOELIX, R.F. 1982. Biology of Spiders. Harvard University Press, Cambridge.

GERTSCH, WILLIS J. 1979. American Spiders, 2nd Edition. Van Nostrand Reinhold Company, New York. 274 pp.

KASTON, B.J. 1970. Comparative Biology of American Black Widow Spiders, Transactions of the San Diego Natural History Society. 16(3):33-82.

LEVI, HERBERT W. 1968. Spiders and their kin. Golden Press, New York. 160 pp. 